\title{
PLASMA-WALL INTERACTIONS IN TANDEM MIRROR MACHINES
}

Steven L. Allen and the TMX-U/MFTF-B Experimental Teams

This Paper Was Prepared For Submittal To

Phystcs of Plasma-Wall Interactions In

Controlled Fusion, NATO Advanced Study

Institute, Quebec, Canada, 8/6-10/84

\section{November 1984}

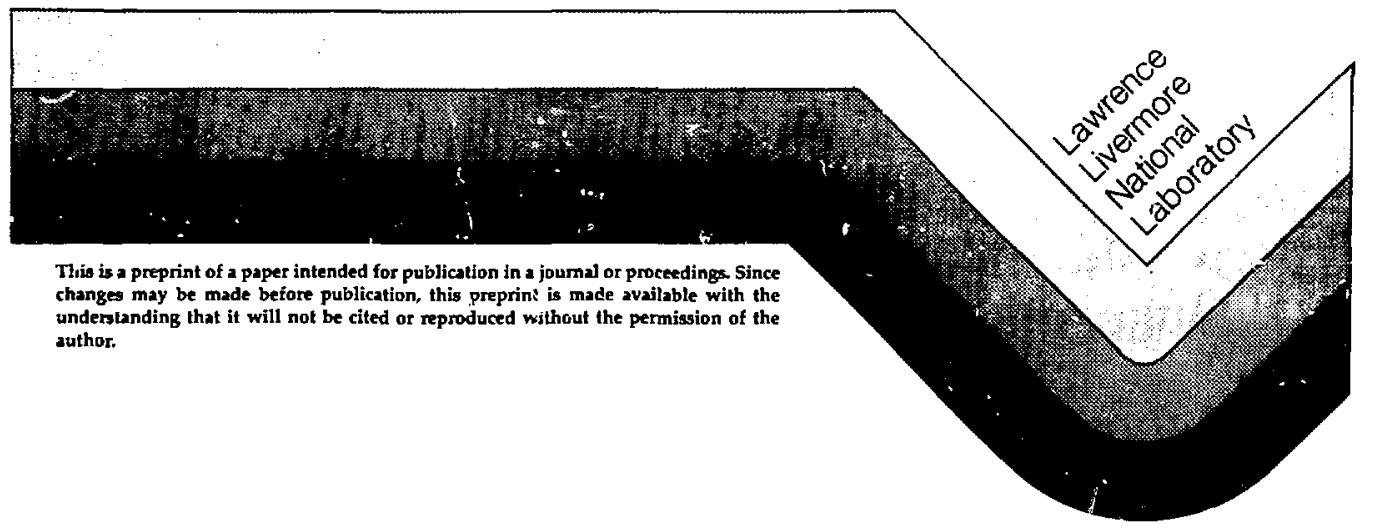




\section{DISCLAIMER}

This repoct was prepared as an account of worth aponsored by an agency of the United Stetes Govemment. Neither tho United States Government nor any atency thereof, aor any of their employeen, make any warsanty, expres or impliod, ot asumes any lecal linbility or reaponaibility for the accusacy, cocspletenca, or unefulneas of ary information, epperatus product, or process dieclosed, or repecsents that its use wold not infrings privately owned rights. Refer. ence herein to any specific commercial product, proceas, it service by trade name, tredemark, monufacturer, or otherwive does not neceasurily conztitute or imply its ondonement, recommendation, or favoring by the United States Government or uny asency thereof. The vitus and opinions of authore expresed berein do not deceasurily state of refinct those of the United Sintes Governatent or any agency thereof.

UCRL -91287

PLASMA-WALL INTERACTIONS IN TANDEM MIRROR MACHINES

Steven L. Allen and the TMX-U/MFTF-B Experimental Teams

Lawrence Liveraore National Laboratory

University of California, Livermore, CA 94550

\section{INTRODUCTION}

Plasma-surface interactione can play an important role in the present generation of tandem mirror machines, such as the Tandem Mirrof Experiment-Upgrade (TMX-U), 1 Phaedrus, 2 Gamma-10,3 and TARA, which are currently operational; and AMBAL, 5 wich will soon be fully operational. The importance of plasma-surface interactions may be even more pronounced in larger, longer-pulse tandem mirrors such as the dirror Fusion Test Facilit 7 (MFTF-B), 6,7 which will be used to investigate plasmas at reactor-like conditions. However, current experiments and models of future experiments indicate that plasma-surface interactions can be minimized in tandem mirror machines. This is in part due to the inherent open field lines of the confinement configuration. In particular, plasmasurface interactions can be controlled at radial surfaces by controlling the axial confinement of the edge plasma.

We present here a description of the plasma-surface interactions in thermal-barrier tandem-mirror machines. The thermal-barrier mode of axial confinemeni is an integral part of a tandem mirror, and it dictates the required plasme conditions, particularly at the surface of the plasma. For this reason, a qualitative discussion of the thermal barrier is presented first in Section 2. A brief description of the experimental configuration used in tandem mirrors to create the thermal barrier is then examined in detail in Section 3; the TMX-U and MFTF-B machines are used as specific examples. In Section 4, the relevant plasma-surface interaction issues are addressed, and experimental results from currently operating tandem mirror machines are included. Section 5 is both a summry and a discussion of future work concerned with plasma-surface interactions in tandem mirrors. 
Several issues are outside the scope of the present discussion and are presented elsewhere. Additional details about experiments concerned with plasma-surface interactions in mirror machines are presented in Refs. 8-10. Reference 11 describes sevaral upgrades to MFTF-B, including steady-state (100-hour) operation with DT fuel and the capability of a very high neutron flux $\left(2 \mathrm{MW} / \mathrm{m}^{2}\right)$ to test various blanket designs. Issues relevant to tandem mirror reactor designs are discussed in Ref. 12.

\section{THE THERMAL-BAFRIER PLASMA ENUIRONMENT}

To understand the importance of the function of a thermalbarrier mode in a tandem mirror, and in turn to appreciate the requirements it places on the plasma-surface interactions, it is necessary to briefly trace the evolution of mirror experiments. Along each step of mirror development, modifications have been motivated by the need for an efficient reactor concept.

The early single-mirror experiments showed that to control magnetohyorodynamic (MHD) stability, tne plasma should be confined in a magnetic well, or "minimum- $B$ " configuration. 13 This requirement motivated the design of highly efficient magnetic geometries, such as the yin-yang quadrupole, ${ }^{14}$ which also have good access for neutral beam injection. Similar magnet designs are used in modern day mirror devices.

The next set of experiments was concerned with the effect of high-frequency modes (on the order of the ion gyrofrequency) on a mirror plasma with neutral beam injection. These modes [such as the drift-cyclotron loss cone (DCLC)] are driven by the non-Maxsellian velocity distributions present in mirror plasmas. 15 These modes cause diffusion in velocity space and can thereby increase plasma losses significantly. Several experiments, including 2 XIİB, showed that the DCLC mode could be stabilized by introducing a low-energy plasma stream. ${ }^{16}$ This was a major breakthough in mirror physics; however, it was also soon realized that a reactor based on a single mirror $j$ jolved a large amount of circulating oower. The expected $Q$ (the ratio of fusion power produced to injected power) from such a reactor was on the order of unity because Coulomb scattering losses imposed a fundamental limit on plasma confinement. 17

The tandem mirror was invented to overcome the reactor limitations of a single mirror, wille incorporating its inhereut advantages. The tandem mirror is composed of two mimimum-B mirror cells (end plugs) with high-energy neutra! beam injection: these are located at each end of a straight solenoidal section (cencral cell). The end plugs provide the MHD stablility for the system, and the central cell plasma furnishes the required lower energy ions for microstability. This configuration adds another dimension to confinement: if the end cell plasma is more dense than the central 
cell, an axial ambipolar potential is established that confines the lons in the central cell. Experiments on TMX showed that the confinement time in a tandem mirror machine could be increased at least an order of magnitude compared with a single mirror. ${ }^{18}$ The plasma was also nearly microstable, exhibiting only low level fluctuations attributed mostly to the Alfvén ion-cyclotron (AIC) mode. 19

In their early form, however, tandem mirror reactor designs required high end-plug magnetic fields and a high beam-injection energy. This is because the ion-confining potential is established by the density difference between the central cell and the end plug; it sca?es logarithmically with density: $\omega=\mathrm{T}_{e} \ln \left(\mathrm{n}_{\mathrm{p}} / \mathrm{n}_{\mathrm{c}}\right)$. On the other hand, the ratio of central-cell fusion power to the injection power required to sustain the end plugs scales as $n_{\mathrm{c}}^{2} / \mathrm{n}_{\mathrm{p}}^{2}$. The electron temperature $T_{e}$ can be increased by auxiliary heating, but it is estimated that to effectively confine a 40-keV central cell plasma with a density of $10^{14} \mathrm{~cm}^{-3}$ would require an end plug density of $10^{15} \mathrm{~cm}^{-3}$, which would in turn require neutral beam injection of $600 \mathrm{keV}$ and peak fields of $17 \mathrm{~T} .20$ These requirements seemed quite restrictive; in addition, the plasma-surface interactions and materials requirements could be quite severe.

The thermal-barrier concept 20 was introduced to ameliorate these requirements. The essence of the idea is to introduce a potential barrier between the end plug and the central cell to more effectively thermally isolate the electrons in these two regions. As a result, each region can be optimized according to its purpose: the central cell plasma can have the high ion energy and density required to produce fusion energy, and the end plug plasma can have a substantially lower ion density but a large ion confining potential to reduce the central cell axial losses. This is achieved by adding $r f$ heating, changing the neutral beam injection angle from perpendicular to the plasma axis to an oblique angle, and adding so-called "ion pumping" of low-energy ions trapped in the thermal barrier.

The thermal-barrier configuration is clarified by comparing the axial plasma potential profiles for three end plug configurations shown in Fig. 1 . Note that $T_{e c}$ is end cell temperature, $T_{e}$ is eleciron temperature, $n_{p}$ is plug density, $n_{p}^{*}$ is passing density in the barrier region, and $n_{c}$ is central cell density. The axial magnetic-field profile is shown in Fig. la, and a schematic of the standard tandem axial-potential profile is shown in Fig. 1b. When the end-plng beam injection is changed to an oblique angle, the sloshing ion mode of operation results (Fig. 1c). The value of the ion-confining potential in this case is equal to that of the conventional tandem. However, the beam-injected mirror-trapped ions (so-called sloshing ions) create an ion-density profile that is peaked off the midplane of the plug, thereby causing a potential 
depression at the midplane; this is advantageous from the standpoint of microstability. It has been shown experimentally that this type of configuration can be created, and that ion fluctuations are low. 21

The thermal-barrier axial-potential profile is shown in Fig. 1d. The dip in the potential near the midplane is the result of two processes: the formation of a mirror-trapped hot-electron distribution by means of electron-cyclotron resonant heating (ECRH), and the removal of ions from the low-potential region by ion pumping. The potential peak is formed by ECRH heating of the electrons in this region. The ion-confining potential can be made quite large while the central cell density is greater than the end plug density because of the low passing-ion density in the barrier region.

The thermal-barrier configuration has also been recently verified experimentally; ${ }^{22,23}$ axial losses of ions can be reduced to nearly zero. Under these conditions, the end plug plasma is quite microstable because of the shape of the axial ion-density profile in the plug (as discusseg above) and the central cell ions that pass into the plug region. ${ }^{4}$ Control of the neutral pressure in these experiments was shown to be very important, both to minimize charge-exchange losses and to minimize the cold plasma that can fill in the thermal barrier potential region. ${ }^{25}$ The edge plasma plays the very important role of shielding the core plasma from neutrals, particularly in the regions where the plasma flux tube is thin. These issues are addressed in detail in Sec. 4.

Several refinements of the thermal barrier concept have recentiy been made. Again, these vere motivated by better understanding of the relevant physics issues and by improved reactor designs.

Perhaps one of the most important issues is the control of radial transport. In a tandem mirror with minimum-B end plugs, the ions $c$ an be transported radially in the central cell by resonant neoclassical transport. As a plasma ion moves from the central cell to the end plug, it passes through a transition region where the magnetic field has a quadrupole component due to the nonaxisymmetric nature of the end plug magnets. As a result, the ion undergoes a radial displacement $\Delta R$ at each end of its axial bounce motion. The major component of this displacement and its direction is proportional to $\cos 2 \psi$, where $\psi$ is its azimuthal angle. Therefore, if one end-plug magnet set is rotated $90^{\circ}$ with respect to the other end, the radial displacements cancel. However, this cancellation is not complete if an azimuthal drift $\Delta \downarrow$ is present as a result of radial electric fields in the central cell. Therefore, the causes for resonint neoclassical transport are nonaxisymetric magnetic fields and azimuthal drifts due to radial electric fields. Detailed explanations of resonant transport are included in Ref. 26. 


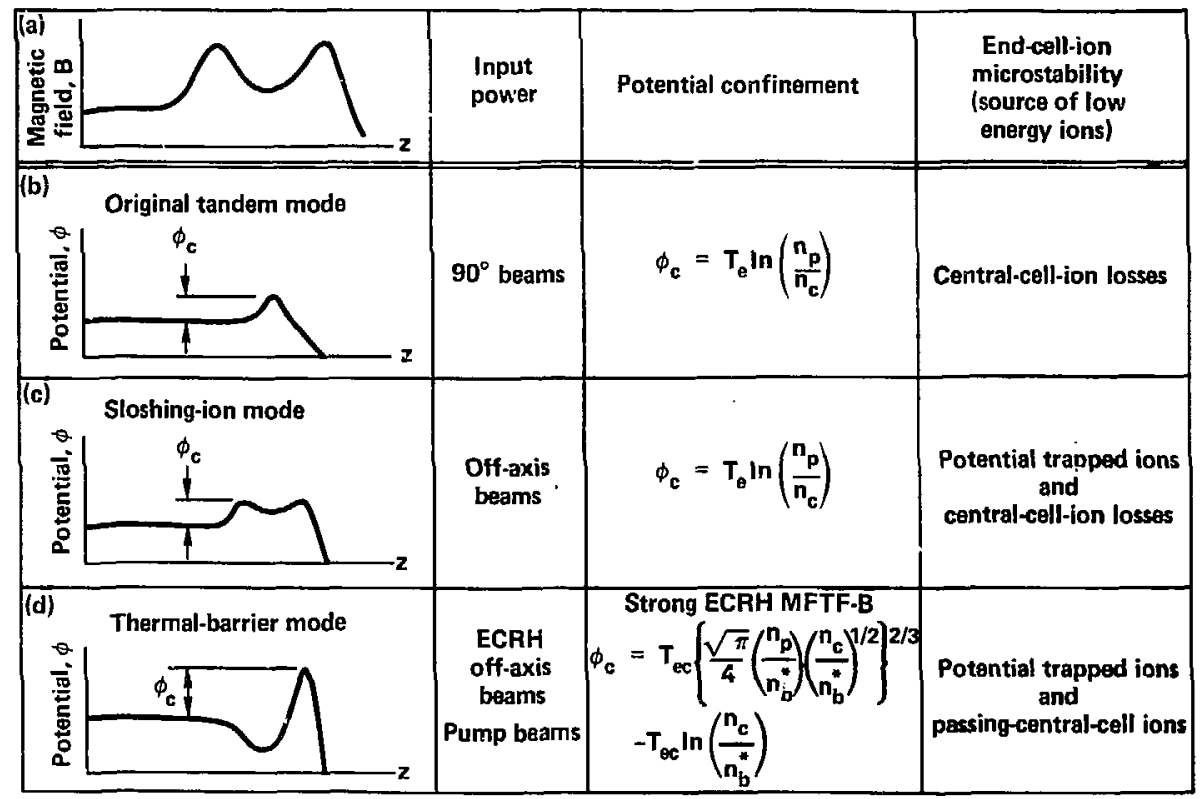

Fig. 1. Tandem mirror operating modes illustrate the thermal barrier configuration in the following illugtrations: (a) the end-plug axial-magnetic-field profile; (b) the axial potential profile for the conventional tandem mode; (c) changing the end plug neutral beams to off-axis injection results in the sloshing-ion mode profile; (d) addition of ECRH and ion pumping is required for the thermal barrier mode. 
Several methods of radial-transport control have been identified. Because one major drive is the shape of the magnetic field, it is desirable to terminate the central cell plasma with an axisymmetric magnet that "throttles" the flow of ions passing into the transition regions. This flow of passing ions is also important for stabilizing trapped particle modes, which are similar to those found in tokamaks. An axisymetic design is incorporated into most current tandem mirror designs. Errors in the end plug field resulting from misalignment can also cause radial transport. This neccesitates the careful alignment during construction, often with electron beams, and the addition of "trim" coils for fine adjustment after installation.

T'1e drive for radial transport is also reduced by controlling the radial-potential profile, (and therefore the radial-electric field), and hence the azimuthal drift. Reducing the radial fields has the added benefit of reducing the rotational drive for instablilites. This radial-field profile is determined by the electron losses along field lines to the ends of the machine. If a negative bias is applied to the end wall, the potential in the central cell will decrease to offset this change. In practice, this bias must be a function of radius, so segmented plates are used. This technique has been demonstrated qualitatively in current experiments. 28

Another improvement is the use of drift pumping to remove ions in the thermal barrier regions. Neutral beams--which remove ions by charge exchange--injected nearly parallel to the axis of the machine ara the more common method. Drift pumping consists of a field supplied by an external coil; the frequency is resonant with a multiple of the bounce or drift frequency of the ions, resulting in a radial displacement. The cumulative result is that the ion eventually leaves the plasma. This technique is attractive because it is selective: it does not pump the sloshing ions, which are not resonant. It is also effective for removing impurities.

The linear geometry of tandem mirrors also makes it possible to directly generate electrical power from any residual axial plasma losses. The conversion efficiency of these devices is usually about $50 \%$. In the original designs, these converters were very large because they depended on the one-dimensional expansion of the plasma fan and subsequent deceleration through a series of grids. Current designs are much more compact because of the use of recircularizing coils to expand the plasma in two dimensions. Gridless converters can be used because the non-ambipolar radial transport in the plasma separates the charge carriers: electrons are collected in the core, and ions are collected at the edge. 


\section{THE THERMAL BARRIER EXPERTMENTAL ENVIRONMENT}

The previous section deait with the plasma physics igsues of a tandem mirror machine in a general way. Next we turn to the experimental environment and how its design addresses these issues. We use two machines at the Lawrence Livermore National Laboratory (LLNL) as specific examples, although other tandem mirror machines are similar in degign.

The goal of THX-U is to demonstrate the thermal barrier concept. The various regions of the vacuum vessel are shown in Fig. 2. The first and second injector regions in the machine contain surfaces that are liquid-nitrogen cooled and titanium gettered to provide pumping of cold gas. These regions control the influx of cold gas into the plasma region from sources such as the neutral beams; they also serve as beam dumps for the energetic neutrals that are not trapped in the plasma. Externai beam lines and dumps are used on other machines such as MFTF-B. The plasma wall is also gettered.

A schenatic of the TMX-U device is shown in Fig. 3a; the axial profiles of magnetic field $B(z)$, electron density of $z)$, and potential $\phi(z)$ are presented in Fig. 3b. Also indicated on these figures are the heating systems: $20-\mathrm{kV}$ neutra1-beam injectors to establish sloshing-ion distributions in the end plugs and to heat the central cell, four $28-\mathrm{GHz}_{z}$ gyrotrons (200-kW each) to provide $E C R H$, and two transmitters (200-kW each) to provide ion-cyclotron resonant heating (ICRH). The time evolution of the heating systems and the plasma parameters for a TMX-U plasma shot are shown in Fig. 4; the east piug, central cell, and west plug parameters as a function of time are presented in each column. Starting at the top of the figure, the plotted quantities are: the ECRH power, the neutral-beam power-supply drain current, the electron density, and the ion end losses as measured by an array of Faraday cups. The time history of the gas fueling in the central cell and the ICRH pulse are also indicated at the top of the Eigure.

The most notable feature of these data is the dramatic reduction in the axial ion loss from each erd when the neutral beams are turned on. This occurs after the tot-electron population is established in the end plugs, and when the sloshing ions are injected with the neutral beams. This configuration has all of the qualicative features of a thermal barrier, but another experiment was performed to verify that the axial potential profile had the same features as a thermal barrier. This experiment is described in detail in Ref. 22, and the major result of the measurement is shown in Fig. 5 from this reference. The experimental setup is shown in the top of the figure; end-loss energy analyzers were used to measure the distribution of escaping ions. The model distribution is shown in the central part of the figure, and the results of the experiment 


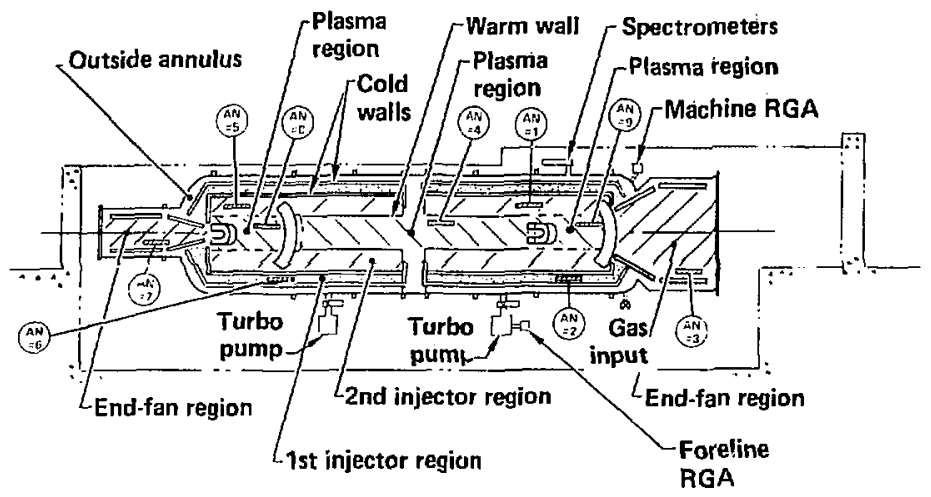

Fig. 2. The TMX-U vacuum vessel. The first and second injector regions act as beam lines to reduce the gas from the neutral beams. Each region contains titanium getter wires.

are shown at the bottom. Note that the model and the experimental profiles have the same qualitative features, thereby verifying the existence of the thermal barrier potential profile. The current experimental program on TMX- $\mathrm{V}$ is focused on achieving these conditions with a higher central cell electron density. After this set of experiments, the magnet set will be made more symmetric by the addition of a throttle coil to examine the issue of radial transport. 29

An example of the next generation of tandem mirror machines is MFTF-B, which is now under construction at LLNL. It is a large (64-it axial length), long-pulse (30-8) machine. The physics goals of $M F T F-B$ inciude confinement of reactor-grade central celi plasmas with ion temperatures up to $15 \mathrm{keV}$, demonstration of high $B$ (the ratio of the plasma pressure to the magnetic field pressure) plasmas approaching 20\%, attaining a plasma-density energy-confinement-time product $n T_{E}$ of approximately $0.6 \times 10^{13} \mathrm{~cm}^{-3} \mathrm{~s}$, and obtaining a DT equivalent $Q$ of approximately 0.4 . These goals represent a significant step toward reactor-type parameters.

In addition, juat as reactor designs have motivated the evolution of mirror-machine physics, they have also placed requirements on engineering technologies. For this reason, another important function of $24 \mathrm{FTF}-\mathrm{B}$ is to allow us to gain experience with some plasma technologies that are relevant to reactors. The design and operation of auperconducting magnets with large cryogenic systems will be demonstrated in MFTF-B. Another goal is to address the issues of 

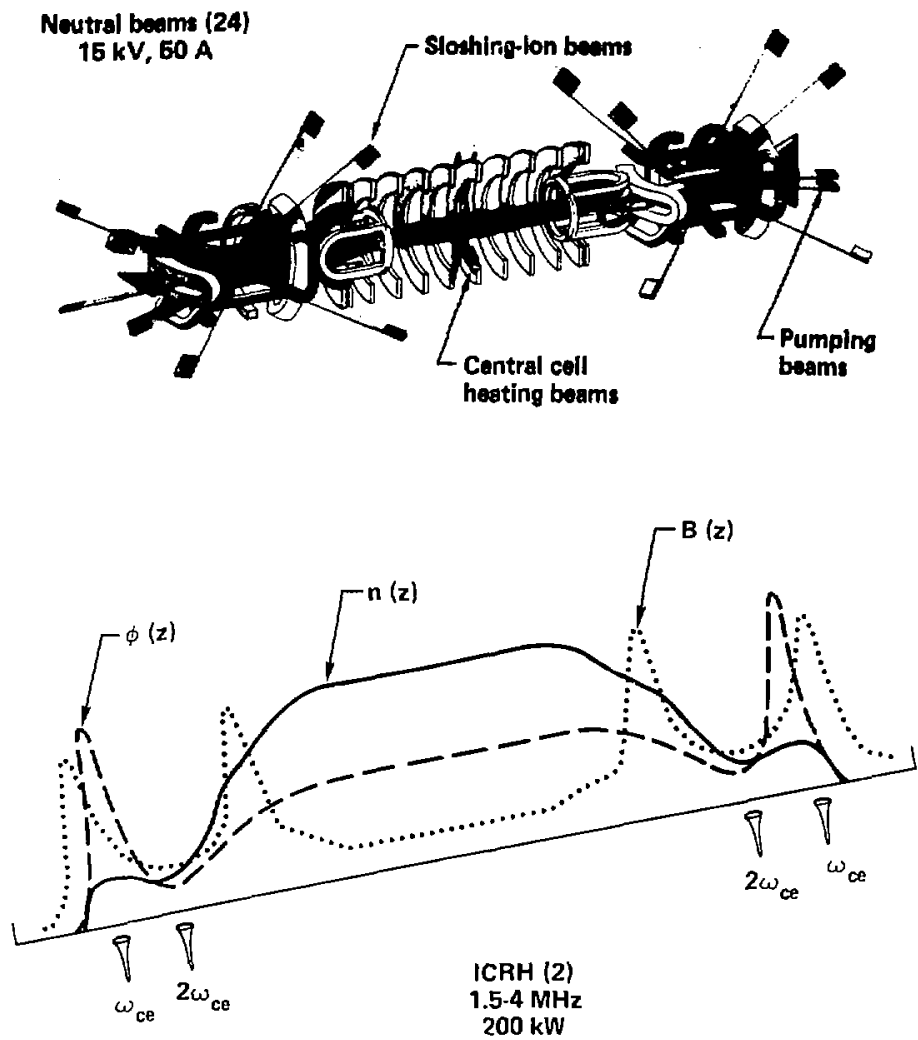

ECRH (4)

$28 \mathrm{GHz}$ gyrotrons

$200 \mathrm{~kW}$ (per tube)

Fig. 3. (a) A schematic of the TMX-U device, illustrating the neitral beam locations and the magnet set. (b) The axial profiles of magnetic field $B(z)$, electron density $n(z)$, the potential $\phi(z)$ are shown along with the locations of the ECRH and ICRH heating systems. 

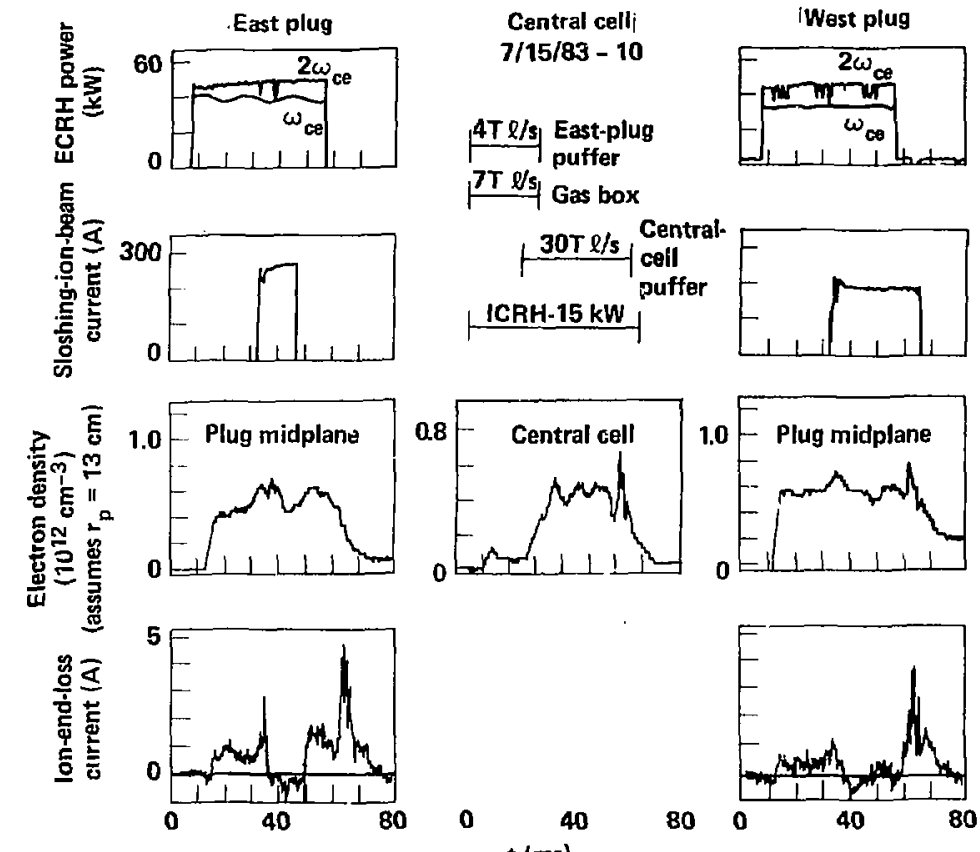

Fig. 4. The time evolution of a plasma shot on $T M X-U$. Shown from top to bottom are the ECRH power, the neutral-beam power-supply current, the electron density, and the ion end-loss current. The quantities are shown for the east plug, central cell, and west plug. The time history of the gas injection systcr and the ICRH power is also shown.

long pulse operation. The 30-s plasma duration of MFTF-B puts new technological requirements on all of the heating systems: neutral beam injectors, ECRH, and ICRH. Nearly steady-state plasma-surface interactions can also be investigated.

The thermal barrier mode for MFTF- $B$ is based on the most recent Mirror Advanced Reactor Study (MARS) reactor design is shown in Fig. 6; the steady-state profiles of pagnetic field, plasma potential, and density are presented. Such a plasma is created in two steps: a 0.5-8 startup sequence followed by $30-5$ steady-state 

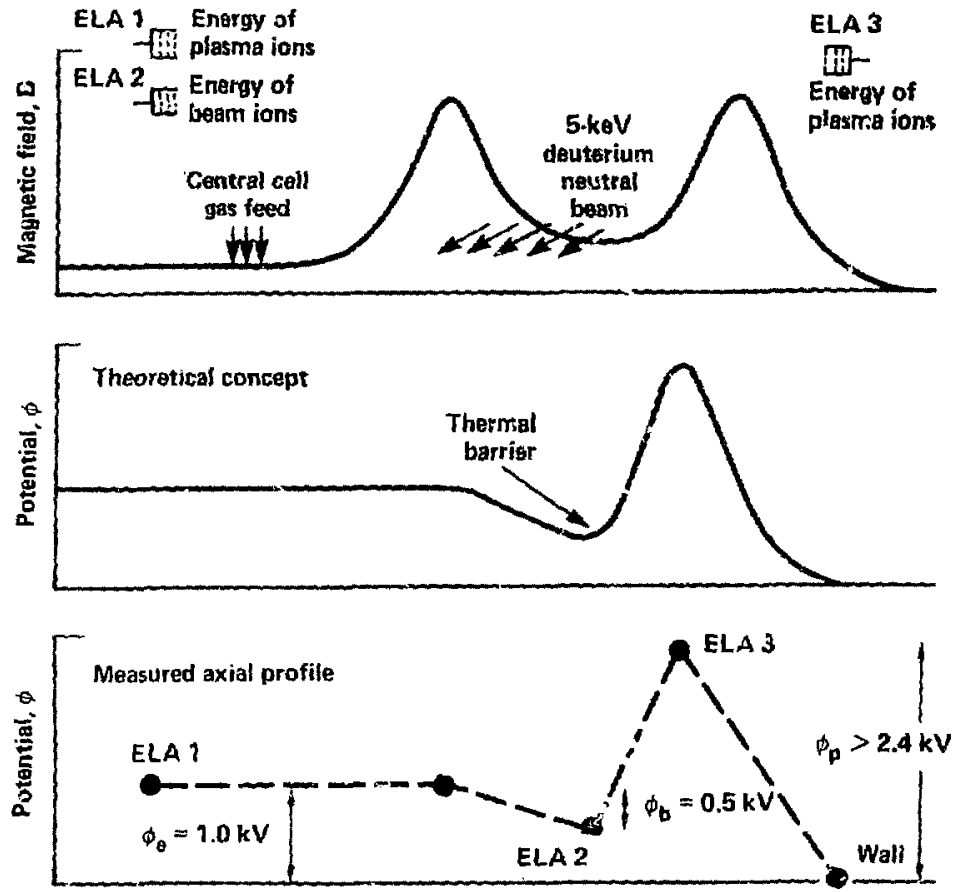

Fig. 5. A schematic representation of the measurement of the thermal barrier potential. profile using three electrostatic ion analyzers to make simultaneous measurements. The experimental setup is shown in the top of the figure. The theoretical and actual axial pocential profiles are compared in the bottom of the figure.

operation. The central cell is designed to have an electron tenperature of $9 \mathrm{keV}$ and an ion tenperature of $15 \mathrm{keV}$. The centra:cell ion-confining potential is dibut $30 \mathrm{kV}$. The high magnetic field region in the axicell decreases resonant radial transport and "throttles" the central cell passing particles to allow operacion in a regitue where crapped particle mc es are minimized, as discussed in the previous section. The yin-y $2 n$, cell provides MHD stability for the syscem. The desired hot electron distribution (with energies up to $500 \mathrm{kEV}$ ) is supplied by ECRH injection at three trequencies in the 

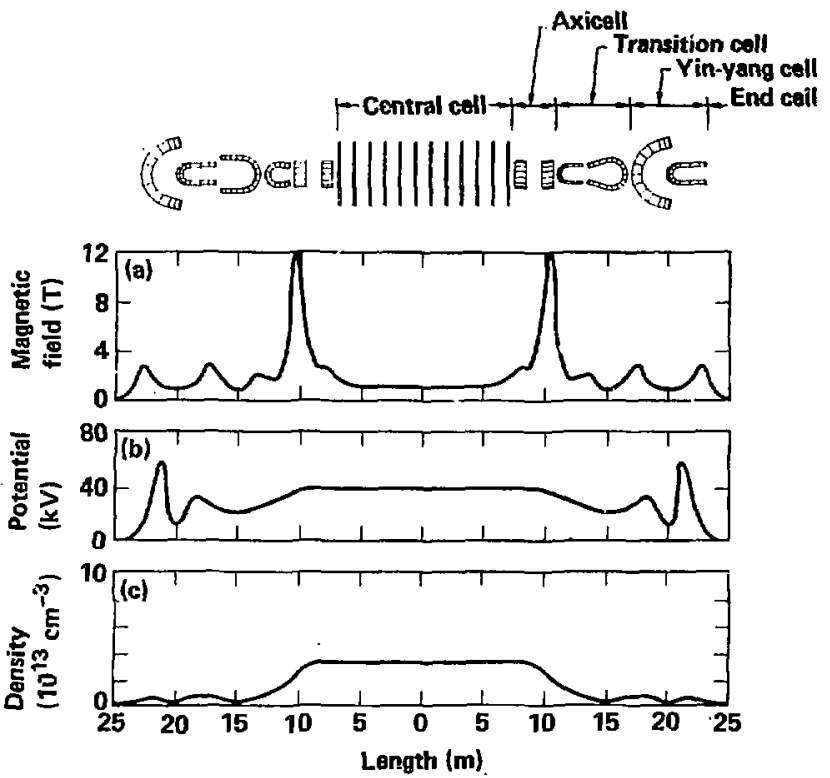

Fig. 6. The axial profiles of magnetic field, plasma potential, and electron density for MFTF-B. The thermal barrier region is in the yin-yang cell.

end plug region. Ion pumping is supplied both by reutral beams in the end region and drift pumping in the transition region.

The vacuum vesse1 and magnetic field coils for MFTF-B are shown in Fig. 7. Note that the overall length of the vessel is about $64 \mathrm{~m}$. The large cylindrical structures on the outside of the machine are input beam lines and beam dumps for neutral beam injectors. Nearly all of the pumping both in the beam lines and in the plasma vessel is by means of liquid-heirum-cooled cryopanelo. A liquid-nitrogen guard jacket surround each cryopanel and the magnet cases. The magnet system consists aí 24 superconducting $\mathrm{Nb}-\mathrm{Ti}$ coils and two high-field $\mathrm{Nb}_{3} \mathrm{Sn}$ insert coils to provide the 12-T field for the aicell region. Also shown in the figure are the trim coils used in the transition region.

Figure 8 depicts the locations of the neutral beam, ECRH, and ICRH heating systems. Each end plug has three quasi-optical ECRH 


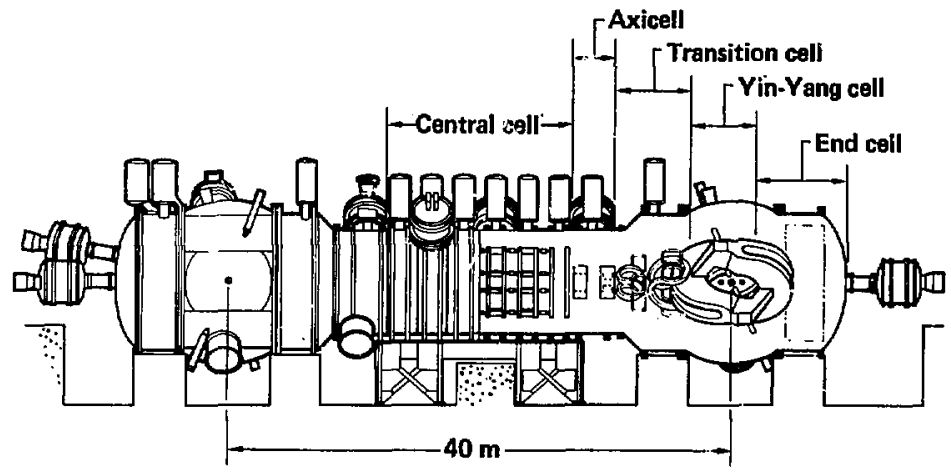

Fig. 7. The vacuum vessel of MFTF-B with its associated neutral beam lines is shown. The right half of tha figure is cut away to show the cuperconducting magnets.

systems. The 56-GHz systems provide $450 \mathrm{~kW}$ at a harmonic of the ECRH resonance to provide a mirror-trapped hot-electron distribution. The $28-$ and $35-\mathrm{GHz}$ systems provide $300 \mathrm{~kW}$ near the fundamental ECRH resonance to develop the potential feak. Two frequencies are required because of the $\beta$ depression by the plasma in this region. These systens are capable of delivering 30-8 pulses.

The ICRH transmitters are located off the midplane of the central cell and provide up to 1 aW of power in the frequency range from 6 to $20 \mathrm{MHz}$ in $0.25-\mathrm{MHz}$ steps. A $40 \%$ coupling efficiency to the plasma is expected during the steady-state conditions. These transmitterf can be operated at this power level for $30 \mathrm{~s}$.

The neutral beams are divided into two classes, $0.5-8$ beams for startup and 30-s beams for sustaining steady-state operation. The 80-kV startup beams are shown in Fig. 8. There are 10 in the central cel1, 1 in each axicel1, and 2 in each yin-yang to establish the sioshing ion population. Each beam is designed to provide $50 \mathrm{~A}$ of neutral current ac the plasma target; the species mix is expected to be $60 / 20 / 20 \%$ for full/half/third energy components. These beams will have gettered arc chambers to minimize impurity influx. The steady-state 30-s beams are designed to provide $10 \mathrm{~A}$ of the ful1energy $80-\mathrm{kV}$ component on the plasma target; two each are located in the axicel1, the yin-yang or sloshing-ion positions, and in the end fans as high-energy pump beams (HEPB). Magnetic separation is used to decrease the current of lower energy species to very low levela 


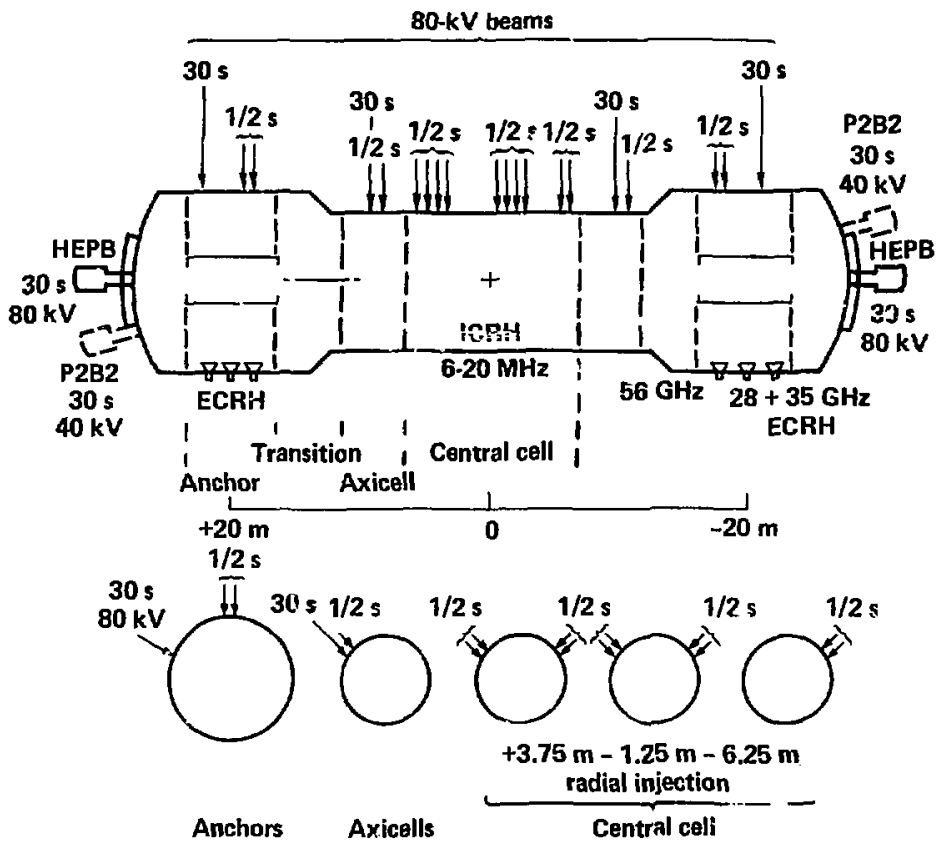

Fig. 8. The neutral beam and $r f$ heating locations for MFTF-B. The bottom half of the figure indicates the azimuthal angle where the $0.5-3$ and $30-8$ neutral beam sources are located.

to minimize barrier filling. In addition, the impurities are reauced to very low levets; this is discussed in more detail in a later section.

Also shown in Fig. 8 are the off-axis $40-k V$ beams (1abeled P2B2) chat had been proposed for ion pumping in the transition region. Recent analysis has determined that these beans must pass very close to magnet structures. Beam scrapeoff introduces a source of cold gas. Baffling the beams is difficult and also reduces the beam current. For these reasons, drift pumping of ions has replaced these beams; the physics of the process is described in Ref. 30 . T'ests of drift pumping will be carried out on TMX-U. Drift pumping is also incorporated into recent MARS reactor designs. 12 In addition, drift pumping has other advantages that are discussed in Sec. 4.2. 


\section{PLASMA-SURFACE INTERACTIONS IN TANDEN MIRRORS}

In a general sense, the plasma conditions for the central cell of a tandem mirror machine are quite similar to other confinement geometries: a dense plasma is confined and heated by suxiliary methods such as ICRH and neutral beams. We might expect that the similarities ia these plasmas would in turn lead to similar plasmasurface interactions. However, this is not the case because even though the core plasmas are similar, the edge plasma in a tandem mirror can be quite different (than toroidal plasmas, for example). In addition, the tandem mirror has an extra resion that contains boch the thermal barrier region and the end wall. Briefly, the tandem mirror allows the possibility of controlling the edge plasma sy means of fueling and transport in this region. This relaxes the severity of the plasma-surface interations, particularly in the fusion-prciucing central cell region. The plasma lost to the end regions can be controlled so that it is well isolated from the wa11. The control of neutrals and impurities is especially important in the thermal barrier region.

The discussion of the relevant plasma-surface interactions can be divided naturally based on the important regions of the machine: interactions at radial surfaces, processes in the thermal-barrierforming regions, and interactiors at the end walls. Impurity generation can be important in all three regions.

\subsection{Plasma-Surface Interactions at Radial Surfaces}

The linear geometry of a tandem mirror mashine allows another degree of freedom for controlling pldswa-su-face interactions at radial surfaces: axipl confinement. In this context, a mirror machine is a "natural" divertor. That is, a region near the plasma edge is formed that has a much shorter axial confinement time than the core of the plasma. In this way, most of the losses of the particles in this edge region flow to the end wall rather than the radial wall. In addition, cold gas and impurities will not have time to penetrate very far before they are lost out of the machine axially. This means that most of the surface interactions will be with neutral atoms, photons, and neutzons.

There is an energy cost to support the edge plasma because as the particles are transported axially they can cause power losses by charge exchange, ionization, and other processes such as radiation. In a reactor, part of this energy could be recovered in the direct converter. In current devices, it puts requirements on the cold gas influx into the system from sources such as neutral beams and on the reduction of reflux from the plasma wall. In the central ceil the plasma is quite dense and the corresponding neutral attenuation is large. The thermal barrier region is more sensitive and is discussed in a subsequent section. 
Control of the plasma radius has been demonstrated experimentally on several mirror machines. The single-cell mirror 2 XIIB experiment showed that the Iadial plasma boundary was determined by the balance of neutral beam fueling and charge-exchange losses on background gas at the plasma edge. 11 In this way, the plasma was not ir direct contace with the radial walls. Furthermore, it was shown on 2 XIIB that the plasma size could be changed by the aiming of the neutral beams; that is, by varying the distance between the axis of the neutral beam and the axis of the magnetic field. This is illustrated in Fig. 9, which contains data from Refs. 8 and 32, The plasma radius (the radial scale length) is plotted as a function of the position of the guiding center (the center of the orbit) of the average particle deposited by the neutral beams. Note that the plasma radius increases as the position of the guiding center is increased from the mognetic centerline. The reason for this change is that the fueling of the edge plasma is increased. Further evidence of this effect is from EUV measurements, ${ }^{33}$ which indicate that the plasma density and temperature drop sharply at the edge of the plasma. Theso experiments demonstrate that the plasma size is ontrolled by the neutral beam fueling.

In a conventional tandem mirror such as TMX, each end plug is similar to the single mirror of $2 X I I B$. In turn, the central-cell plasma radius is controlled by the end-plug radius because the end plug is responsible for establishing the potential and, hence, axial confinement. Specifically, the radial density profile determines the radial dependence of the axial potential profile, which in turn determines the radial profile of axial confinement. In the TMX experiment, the end-plug plasma radius was determined by neutral beam aiming; the radial profile of the line density is shown in Fig. 10a, which contains data frow Ref. 8. When the flux tube containing this plasma is rapped into the central cell, it is inside any physical limiters, as shown by the data in Fig. 10b. In this way, the plasma density and temperature are very low near the central-cell radial 1 imiters, thereby minimizing any plasma-wall interactions.

The same type of radius contro? is possible in a thermal-barcier end plug. The radial extent of the barrier is determined by several processes, including charge exchange of sloshing ions by cold gas, neutralization of the therma - barrier potential by cold ions and electrons, spatially dependent pumping by neutral beams, and spatially dependent ECRH heating. For the most part, these processes favor the formation of a thermal barrier in the core of the plasma, with a lower confinement time at the jage. As shown in Fig. 11, these conditions in the end plug determine the axial confinement of the central cell, and thereby the plasma edge.

Results from TMX-U indicate that this configuration can be established. Under certain conditions, the axial-end-loss current 


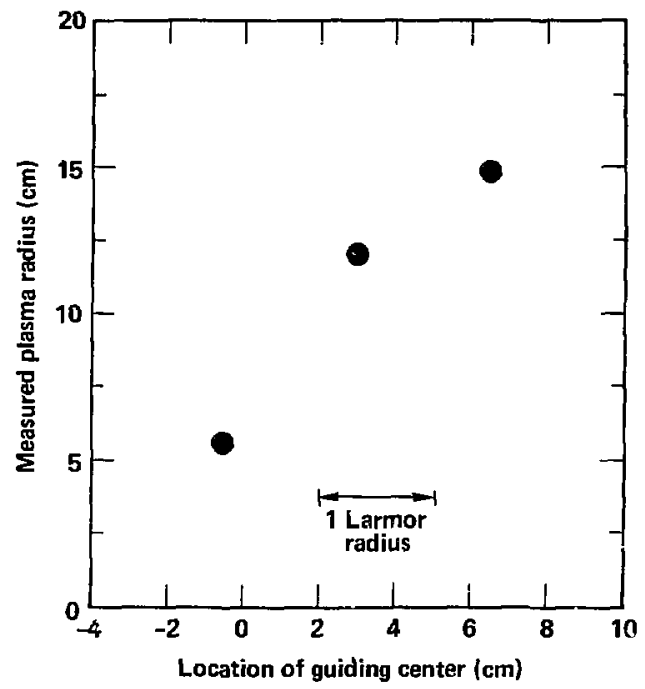

Fig. 9. Data from $2 X I i B$ indicate that the plasma size depends on the aiming of the neutral beams. The plasme radius (the radial scale length) is plotted as a function of the position of the guiding center (the center of the orbit) of the average particle deposited by the neutral beams.

as measured by an array of Faraday cups on the end wall is small in the core of the plasma, while the current at the edge is larger. A second signature of the influence of the edge plasma in these experiments is the observation of a pressure rise in the end fan region near the end wall during plasma operation. ${ }^{25}$ This indicates that plasma is being transported to the end wall by the edge plasma. An example of this data is shown in Fig. 12 from Ref. 25. Note that the pressure first rises at the beginning of the plasma shot. When the thermal barrier is formed and the core axial ion losses decrease at $25 \mathrm{~ms}$, the pressure stabilizes at a fairly constant level determined by the axial losses of the edge plasma.

Yet another type of radius control is possible based on the control of radial transport in the plasma by biasing the end wall as discussed in Sec. 2. If a region near the edge of the plasma is not biased, then the radial electric field will exist, which can drive resonant transport. In this way, the particles at a certain radius experience radial transport into the edge plasma and cannot support 


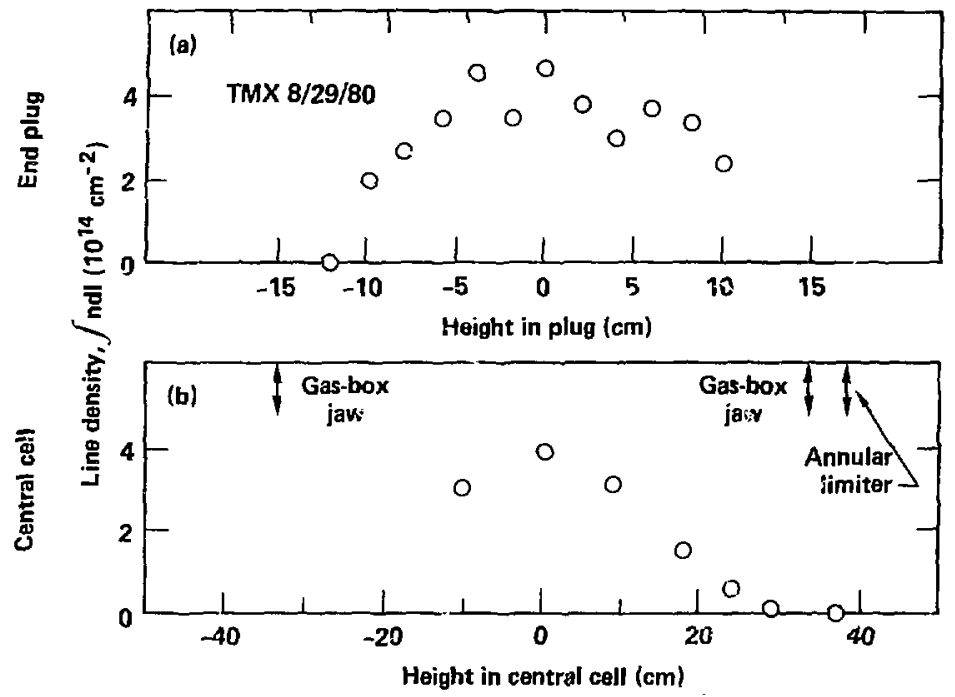

Fig. 10. Data from TMX demonstrate that the central cell plasina can be isolated from the limiter. The radial profiles of the end plug ( $a$ ) and central cell (b) 1 ine densities are shu:s. Note that the line density is low near the radial initers in the central cell. The radius of the end plug plasma rar used to control the central cell plasma.

the corc plasma; this defines the plasma edge. This technique hi's the advantage that the plasma radius can be varied without changing any other parameters. Details of the plasma radius control for MFTF-B and MARS are presented in Ref. 33.

The edge plasma operation discussed above will only be efficient if its power requirements are reasonable, that is, if impurity generation and reflux are minimized. In addition, the machine will have to be cleaved initially to obtain optimum operation. Plasma wall conditioning techniques will be required. TMX-U and MFTE-B contain a plasma wr.11 to shield the plasma from any direct path to a cold surface sucli as a cryopanel or magner. case. Several methods have been used to condition the walls of mirror machines, including: (1) cleaning by repetitive plasma shots, (2) glow dischurge cleaning $(\mathrm{CDC})$, and (3) titanium gettering. 


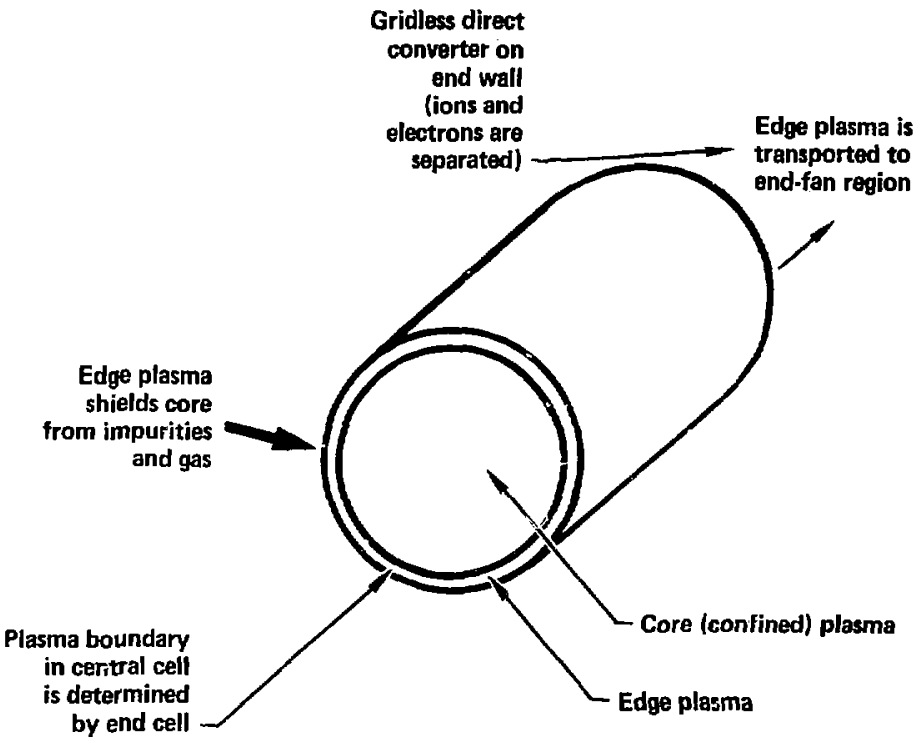

Fig. 11. A schematic representation of the edge plasma and how it can be used to minimize the interactions at radial walls.

The major disadvantage of the first technique in current operating machines is the low duty cycle. In machines like MFTF-B where 30-s neutral beam operation is possible, it should be much more useful. It may also be possible to maintain a cleaning plasma with other heating methods such 95 ECRH and ICRH, which could be designed for even longer pulses. 34,35 The second technique has been used successfully on TMX- $U,{ }^{36}$ essentially replacing method $(1)$ on this machine. The GDC results have been very similar to those obtained on tokamaks; ${ }^{37}$ a typical 4 srue of the 16 amu peak as a function of time is shown in Fig. 13.38 The decay has a $t^{-1}$ dependence, similar to Ref. 37. The major function of GDC in TMX-U is to remove hydrocarbons. Some water removal may occur, but the GDC is carried out at room temperature, so the removal rate is slow.

On MFTF-B, GDO may be somewhat more complicated, as the magnetic field must be off and the pumping capacity of the fryopumping system may be exceeded during extended operation at the required pressures. This requires operation of GDC without the cryopanels and with auxiliary 

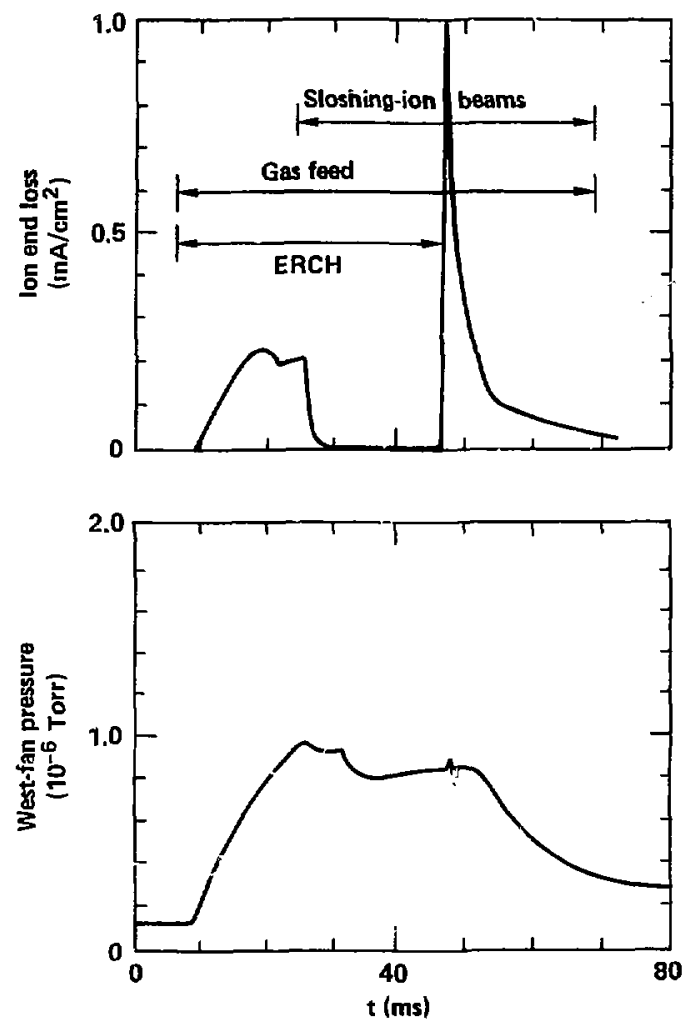

Fig. 12. The time history of the ion end loss (top) and end fan pressure (bottom) as a function of time. Note the initial rise of the end fan pressure, which then stabilizes or decreases when the end losses decrease.

pumping. In addition, specialized coatings on the cryopanel surfaces may be degraded by the GDC, although experiments ${ }^{39}$ have shown that electrical isolation of the cryopanels will minimize this damage.

Another important wall conditioning technique is titantium gettering. A substantial fraction of the internal TMX-U surface 


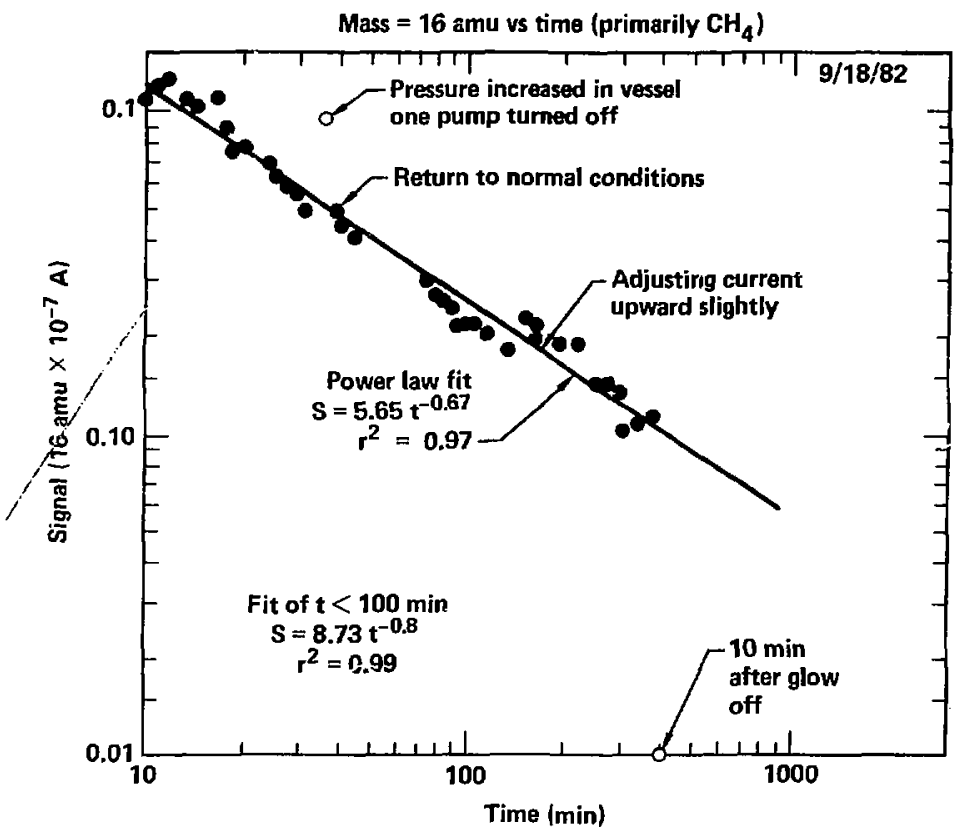

Fig. 13. The RGA signal from 16 amu vs time during GDC is shown. The production rate varies nearly as $t^{-1}$.

area $(>90 \%)$ is titaniumgettered. Getter wires are supported between each set of liners and inside the plasma wall so that both sides of these surfaces are gettered. A staged getter cycle, starting with the outside of the machine and working inward, is used to deposit a fresh layer before each plasma shot and pump gas away from the plasma region. Surface analysis of probes inserted near the plasma wall have found that the average film thickness is approximately 6 to 10 monolayers per shot. The resulting pumping speeds exceed $10^{6} \mathrm{l} / \mathrm{s}$; decails of these measurements are presented in Ref. 40.

Residual gas analyzer ( $R G A$ ) measurements during gettering indicate that mathane is produced presumatly by the hot getter wire interacting with hydrogen. A significant fraction of the $10^{-8}$-Tor 
$\left(10^{-6}-\mathrm{Pa}\right)$ base pressure before the plasma shot is methane. Cryopumps actively pump the methane, and the liquid-nitrogen-cooled (Ti-gettered) liners pump methane away from the plasma region by physisorption to the surface,

Auger electron spectroscopy (AES) analysis of probes inserted near the wall and exposed to a series of getter and plasma sequences reveals a substantial amount of oxygen ( $130 \%$ ) present in the gettering. This may be the result of the pumping of water by the titanium films. Furthar details are presented in Ref. 41; this result is undergoing further study at this time.

In present experiments, impurity concentrations and radiated power are quite low, as indicated by the data in Table 1 . This is presumably due at least in part to the extensive titanium gettering. In addition, the edge plasma shields the core from impurities. Shown in Fig. 14 from Ref. 42 is the total oxygen density as a function of radius. These data were obtained during an impurity injection experiment where gas impurities were injected inco the edge of the plasma. Several plasma shots were required to measure the radial profiles of all of the ionization states of oxygen. All of these data were then Abel-inverted and divided by the electron density profile to obtain the data in Fig. 14. Note that the tota! oxygen density is peaked at the edge of the plasma, and does not penetrite efficiently into the core.

\subsection{Plasma-Surface Interactions in the Thermal Barrier Region}

The thermal barrier region is perhaps the most critical from the standpoint of plasma-surface interactions. To sustain the thermal barrier potential profile, the neutral densicy and impurity concentrations must be carefully controlled. Specifically, the neutral density must be kept low to minimize the charge-exchange

Table 1. Comparison of impurity soncentrations and power loss for the central cell of TMX and of TMX-U.

\begin{tabular}{|c|c|c|c|c|}
\hline \multirow[t]{2}{*}{ Species ${ }^{a}$} & \multicolumn{2}{|c|}{ Impurity Concentration (\%) } & \multicolumn{2}{|c|}{ Power loss $(\mathrm{kW})$} \\
\hline & TMX & $\mathrm{TMX}-\mathrm{U}$ & TMX & TMX-U \\
\hline Carbon & 0.08 & 0.06 & 1.5 & 0.3 \\
\hline Nitrogen & 0.10 & 0.20 & 1.5 & 0.7 \\
\hline Oxygen & 0.40 & 0.80 & 6 & 2.7 \\
\hline Tiranium & 0.10 & None & 10 & None \\
\hline Deuterium & & & 6 & 0.1 \\
\hline
\end{tabular}

The He-like C V, N VI, and OVII are not included in this table. 


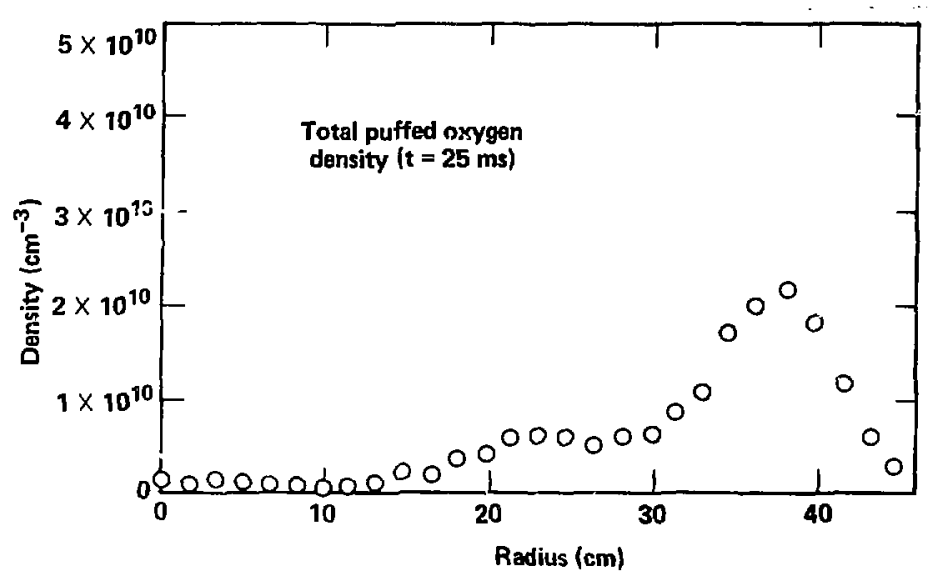

Fig. 14. The radial profile of the total oxygen density as a function of radius is shown. These data were cbtained from impurity puffing, experiments on TYX. Note that the impuritiss do not peretrate efficiently into the central cell plasma.

loss of sloshing ions and the trapping of cold electrons and ions in the end plug regicn. Cold ions neutralize the dip in the thermal barrier fotential, and cold electrons decrease the potential peak in the end plug. This means that the combination of shielding and particle removal by the edge plasma, the ion pumping in this region, and the control of cold gas sources from neutral beams and wall reflux must be sufficient to prevent these loss processes from becoming important. In addition, impurity ions can become trapped in the potential dip and neutralize the thermal barrier potential.

The importance of the control of neutral gas is demonstrated by TMX-U results shown in Fig. 15 from Ref. 25; the pressure in the end plug and the ion end losses are shown as a function of $z$ ime for two cases. In the left half of the figure, the neutral beam gas and wall refiux are not carefully controlled, and the end losses increase when the end plug pressure rises. After these data were taken, extersive baffing of the cold gas from the neutral beams was added to the TMX-U experiment and the wall reflux was reduced by more efficient wall conditioning. (Recall that this experiment ooes not have separate external beam lines for the neutral beams; they are an integral part of the vacuum vessel.) This change produced the datain the right half of the figure; note that the end plug pressure is lower and the end losses remain at a low value for a longer period of time. 
(a) Before vacuum modifications 2/18/83 S-34
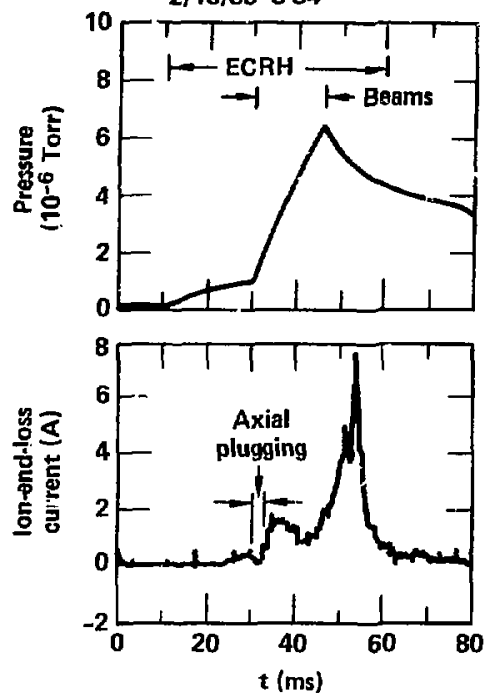

(b) After vacuum modifications $7 / 5 / 83$ S-30
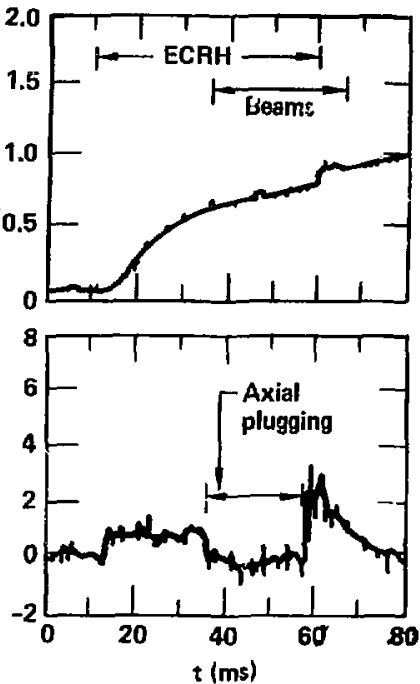

Fig. 15. Data from TMX-U show that control of the pressure in the end cells is important for thermal barrier operation. The end plug pressure and ion end loss is shown for two cases: (a) before vacuum modifications, and ( $b$ ) after extensive neutral beam baffling was added and more effective wall conditioning was carried out. Note the pressure is lower and the axial plugging (reduction of end losses) persists for a longer time after the vacuun improvements.

These same measures have been incorporated into the MFTF-B vacuum system. Neutral bear injectors, when possible, are connected to the vessel through a beam line with extensive differential pumping. When it is necessary to locate the beam closer to the plasma, the beam line is incorporated into the machine by installing baffles and pumping. Beam dumps are located in separate tanks across from the beam, or in large pumping chambers incorporated into the vessel. A schematic of an external beam line and an internal beam dump is shown in Fig. 16. Reflux is controlled by wall conditioning techniques, especially gettering. 

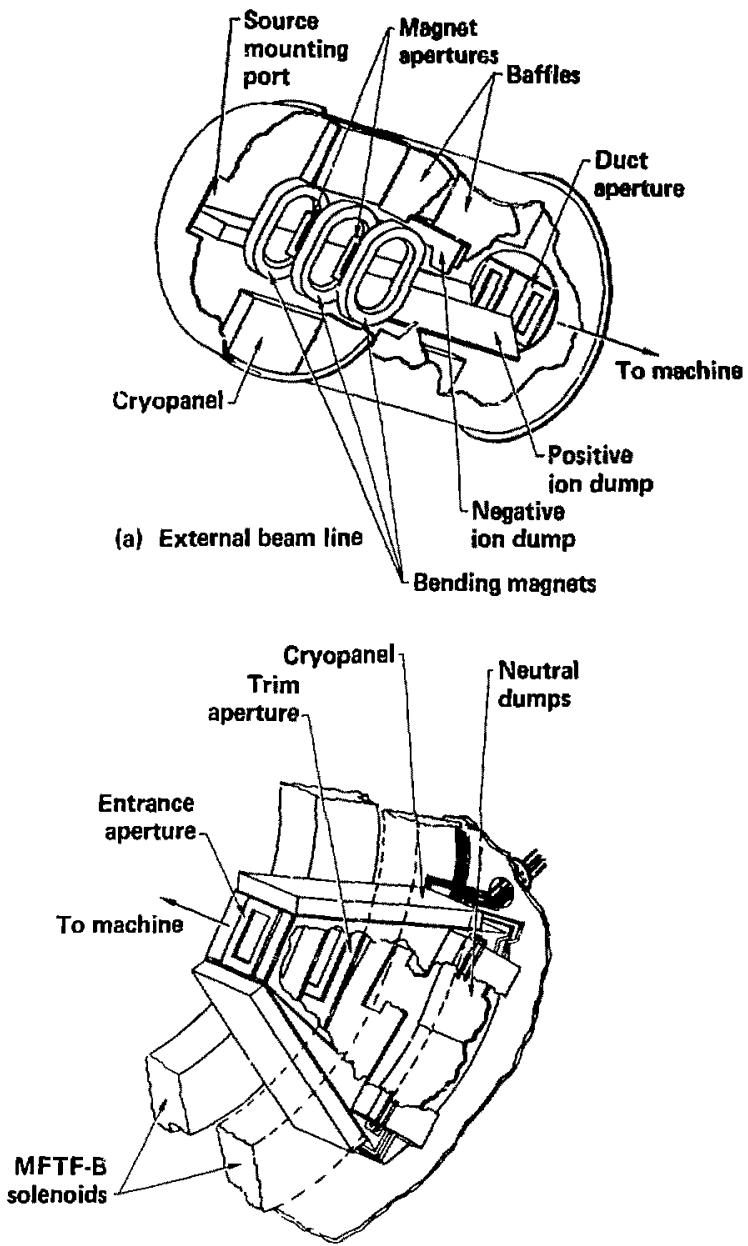

(b) Internal beam dump

Fig. 16. A schematic representation of the external beam lines and integral beam dumps for MFTF-B: (a) external beamline, (b) internal beam dump. These are important for the reduction of gas, particularly in the thermal barrier region. 
A mude 1 of the gas pressure in the end regions of TMX-U has been developed; ${ }^{25}$ gas sources due to beam injection and wall reflux have been included. This model indicates that the pressure outside of the TMX-U plasma should be less than $0.5-1 \times 10^{-6}$ Torr. This model is in qualitative agreement with the experimental results. Similar calculations for MFTF-B have been carried out. Trapping of cold neutrals in the thermal barrier region has been found to be the most important limiting process. This establishes a reguirement of maintaining the on-axis neutral density below $10^{7}$ to $10^{8} \mathrm{~cm}^{-3}$ in this region. A gas penetration code ${ }^{43}$ is then used along with the - spected plasma parameters to calculate the neutral attenuation by ihe plasma, which determines the neutral density at the edge plasma. The model indicates that the edge pressure must be in the range from $10^{-7}$ to $10^{-6}$ Torr. This pressure must be consistent with the supplied pumping speed of the system and the sources. Calculations indicate that the requirements can be met, as long as wall reflux does not exceed unity by a large amount and gas sources from neutral beams are well controlled.

Impurities can also degrade the thermal barrier because they are efficient1y trapped in the potential minimum. Cold impurities are expected to be shielded from the barrier region by the edge plasma. However, impurities present in neutral beams that are used to fuel and pump the thermal barrier cait penetrate into the core. Figure 17 shows impurity emissions from several oxygen, nitrogen, and carbon lines during a plasma shot on TMX-U. Note that the nitrogen and oxygen emissions decrease rapidly when the neutral beam is turned off, indicating that the beam is a source of these impurities. Estimates indicate that about $1 \%$ of the beam current in normal injectors can be oxygen. 44 Because these impurities can be sodetrimental, two steps have been taken in the beam sources. In the TWX-U sources and the $0.5-\mathrm{s}$ beams for MFTF-B, the arc chambers are gettered; tests have shown that this can reduce the impurity current to less than $0.1 \%$. For the 30 -s MFTF-B sources, magnetic separation is incorporated into the design, a schematic of such a source is shown in Fig. 18. The expected impurity current from this source is in the range of 0.001 to $0.0001 \%$; these sources are currently being tested. Models have shown than this reduction should be sufficient for thermal barrier operation in MFTF-B. 45

Finally, it should be noted that other means of pumping the thermal barrier region, such as drift pumping in MFTF-B, should also be advantageous from the standpoint of plasma-surface interactions. In this method, which is not expected to produce any neutral gas or impurity influx, ions are moved radially to the edge plasma, where they are transported to the end fan regions and are pumped. This is in contrast to neutral beam pumping, where ions are charge-exchanged into neutrals that are lost in the pumping region. In addition, it should be possible to selectively pump impurities from the system. 


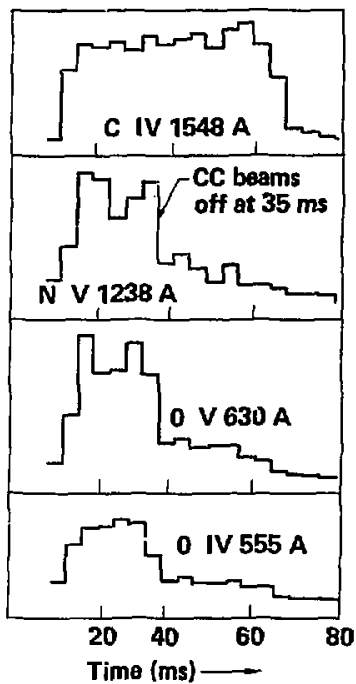

Fig. 17. Daia from TMX show the time histories of carbon, nitrogen, and oxygen ionization states. During the plasma shot, the neucral beams were turned off and oxygen and nitrogen emissions decreased dramatically. This indicates that the neutral beam is the source of these impurities.

\subsection{Plasma-Surface Interactions at the End Walls}

In early mirror machines, a target plasma was injected along field lines by a plasma gun. This created a plasma between the end wall and the magnetic mirror that could cause large power iosses. ${ }^{6}$ This problem was minimized by the use of a pulsed plasma gun and pulsed magnetic fields, thereby breaking the connection to the end,wall. In modern tandem mirrors, ECRH is used to initiate the plasma 47 for thermal barrier operation, and this mode of startup is also planned for MFTF-B. ECRH startup also removes one, source of impurities because some plasma guns injected titanium ${ }^{48}$ directly into the plasma.

Control of the plasma density in the neighborhood of the end wall is important to minimize power losses. A fraction of hot ions is not confined and is lost to the end wall; the density of these ions can be controlled by expanding the plasma flux tube, which is accomplished by 


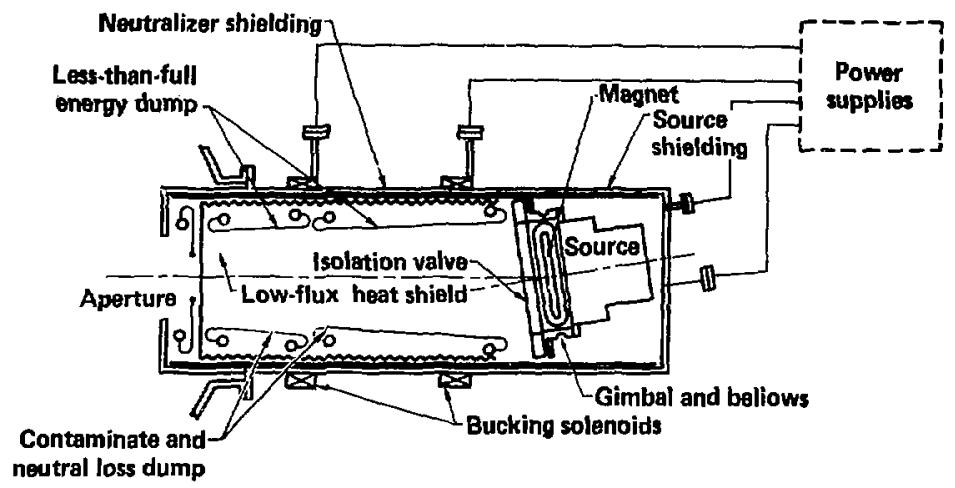

Fig. 18. Schematic of the pure beam injectors for HFTF-B. These beams provide $10 \mathrm{~A}$ of full energy, low impurity current.

decreasing the magnetic field from the outside mirror point to the end wall. Explicitly, $n_{w}=n_{m}\left(B_{w} / B_{m}\right)\left(V_{m} / V_{w}\right)$, where $n$ is the ion density, $B$ is the magnetic field, and $v$ is the velocity parallel to $B$; the subscripts $w$ and $m$ refer to the wall and the mirror point, respectively. The density reduction was experimentally verified on TMX, where the magnetic field ratio was about 200.49 On MFTF-B, the magnetic field ratio is equal to 60 .

A second source of power loss could be caused by the cold ions produced from recycling at the end wall. The cold neutrals produced by interactions with the end wall must be pumped before they ionize and accumulate in the end region. The plasma density control discussed above plays a role in this process, as the mean time between ionizations will be longer at low density, resulting in a higher gumping probability. A model has been computed for TMX-U and METF-B 56 that indicates that gas accumulation should not be a problem with the available pumping.

The potential near the end wall can also be important. It has been shown experimentally that the electron temperature near the end wall can be small, which leads to a small sheath potential, reducing the probability of unipolar axcs. 9 Secondary electron emission at the end walls was once thought to be a major problem in mirror machines, limiting the electron temperature by allowing hot electrons to escape. ${ }^{46}$ When space charge 1 igjting effects were considered, as in the mode 1 diacussed above, 50 it was found that only modest increases in the end loss power would occur. In the case of MFTE-B, an enhancement of only $40 \%$ is predicted for a 
particle reflux coefficient of unity even if the electron temperature near the end wall is equal to the central cell temperature. The actual temperature in the region near the end wall is expected to be much less than this value, so the effect of secondaries is expected to be even smaller.

Impurity generation in this region is not anticipated to be a problem, as ions must penetrate the large axial potential to influence the rest of the plasma region. Radiation losses should be small for impurities in this area because the electron density and temperature are low.

\section{SUMMARY}

There are indications boch from operating experiments and theoretical models that plasma-surface interactions may be minimized in thermal harrier tandem mirror machines. The interactions occur in three primary regions: at radial surfaces, in the thermal barrier, and at the end wall. Interactions at radial surfaces can be minimized by controlling the radial profile of the axial confinement of the plasma. One method of accomplishing this is to control the radial extent of the themal barrier. In the thermal barrier region, the control of cold gas and impurities is very important, requiring gas control in the neutral beams and also impurity control by gettering and magnetic separation. In the end wall regions, flux tube expansion of the plasma and control of gas recycling can be used to minimize plasma wall interactions.

We have used the results from the TMX-U machine as an example of currently operating devices. The thermal barrier potential profile has been established in this experiment. New experiments are beins planned on TMX-U and other experiments to optimize the control of plasma surface interactions, including metal vapor jets to control neutral beam gas, and operating with high temperature plasma walls. 4 Diagnostic techniques are also becoming much more sophisticated, including laser fluorescence measurements of the neutral density. 51

This work was performed under the auspices of the U.S. Department of Energy by the Lawrence Livermore National Laboratory under contract number $W-7405-E N G-48$. 


\section{REFERENCES}

1. T. C. Sinonen, D. E. Baldwin, S. L. Allen, "TMX Tandem Mirror Experiments and Thermal-Barrier Theoretical Studies, "in Proc. 9th Intern. Cunf. Plasma Physics and Controlled Nuclear Fusion Research, held in Baltimore, MD, 1982 (IAEA, Vienna, 1983), Vol. 1, p. 519.

2. N. Hershkowitz, R. A. Breun, D, Broushous, "Recent Experiments in the Phaedrus Tandem Mirror," in Proc. 9th Intern. Conf. Plasma Physics and Controlled Nuclear Fusion Research, Baltimore, MD (1982), IAEA, Vienna, 1983, vol. 1, p. 553 .

3. M. Inutake, K. Ishii, A. Itakura, "Studies of Improvement of Plasma Confinement in Axisymmetrized Tandem Mirror," in Proc. 9th Intern. Conf. Plasma Phusics and Controlled Nuclear Fusion Research, Balrimore, MD, (1982), IAEA, Vienne, 1983, vol. 1, p. 545 .

4. J. Kesner, R. S. Post, B. D. McVey, anj D. K. Smith, "A Tandem Mirror with Axisymmetric Central-Cell Ion Confinement," Nuc. Fus. 22 549-560 (1982a).

5. G. I. Dimov and G. V. Roslyakov, A Trap With Ambipolar Plugs, (institute of Nuclear Physics, Novosibirst, ussR, Preprint 80-1520), published by Lawrence Livermore National Laboratory, Livermore, CA, UCRL-TRANS-11670 (1981).

6. D. E. Baldwin, B. G. Logan, T. C. Simonen, Physics Basis for MFTF-B, Lawrence Lirarmore National Laboratory, Livermore, CA, IIC ID-18496 (1980).

7. K. I. Thomassen, V. N. Karpenko, An Axicell Design for the End Plugs of MFTF-B, Lawrence Livermore National Laboratory, Livermore, CA, ICID-19318 (1982).

B. R. P. Drake, Nuclear Technology/Fusion 3405 (1983).

9. W. L. Hsu, "Review of Plasma Wall Interaction Experiments on TMX and TMX-U," in Proc. 6th Intl. Conf. on Plasma-Surface Interactions in Controlled Fusion Devices, Nagoya, Japan (1984). To be published in the J. of Nucl. Instr. and Mater.

10. S. L. Allen and the TMX-U/MFTF-B Experimental Team, "Plasma-Surface Interactions in Large Tandem Mirror Devices--MFTF-B" in Proc. 6th International Conference on Plasma-Surface Interactions in Contralled Fusion Devices, Nagoya, Japan (1984). To be published in the J. of Nucl. Instr. and Mater.

11. K. I. Thomassen, B. G. Logan, J. N. Doggett, and F. H. Coensgen, "A DT-Burning Upgrade to MFTF-8", in Proc. 6th Intl. Conf. on Plasma-Surface interactions in Controlled Fusion Devices, Nagoya, Japan (1984).

12. B. G. Logan, MARS Final Report, Lawrence Livermore National Laboratory, Livermore, CA, UCRL-53480 (1984).

13. C. C. Damm, J. H. Foote, A. H. Futch, A. L. Gardner, and R. F. Post, Phys. Rev. Lett. 13464 (1964). 
14. R. W. Moir and R. F. Post, Nucl. Fusion 9253 (1969).

15. R. F. Post, in Proc. Intl. Conf. Plasma Confined in Open-Ended Geometry (Gatlinburg, TN, 1967), p. 309; also published as Oak Ridge National Laboratory, Oak Ridge, TN, CONF-671127.

16, F. H. Coengsen, W. F. Cummins, B. G. Logan, A. W. Molvik, W. E. Nexsen, T. C. Simonen, B. W. Stallard, and W. C. Turner, in Proc. 7th Eur. Conf. Cont. Fusion Plasma Phys., Vol. II, p. 167 (1975).

17. R. W. Moir, Standard Mirror Fusion Reactor Design Study, Lawrence Livermore National Laboratory, Livermore, CA, IICID-17644 (1978).

18. D. L. Correll, Nuc. Fus. 22223 (1982).

19. T. A. Casper andG. R. Smith, Phys. Rev. Lett. 481015 (1982).

20. D. E. Baldwin and B. G. Logan, Phys. Rev. Lett. 431318 (1979).

21. T. C. Simonen, Phys. Rev. Lett. 50 1668 (1983).

22. D. P. Grubb, S. L. Allen, J. D. Barter, "Thermal Barrier Production and Identification in a Tandem Mirror," submitted to Phys. Rev. Lett.; Lawrence Livermore National Laboratory, Livermore, CA, UCRL-90536.

23. T. C. Simonen, S. L. Allen, T. A. Casper, "TMX-U Experimental Results," in Proc. of Course/Workshop on Mirror-Based Approaches to Magnetic Fusion, Varenna, Italy, Sept. 7-17, 1983; published by Lawrence Livermore National Laboratory, Livermore, CA, UCRL-892B6 (1983).

24. T. A. Casper, L. V. Berzins, R. F. Ellis, R. A. James, and C. Lasnier, "Microstability of TMX-U During Initial Thermal Barrier Operation," in Proc. of Int 1. Conf. on Plasma Physics, Lausanne, Switzerland (1984); Lawrence Livermore National Laboratory, Livermore, CA, UCRL-90451.

25. W. C. Turner, W. E. Nexsen, S. L. Allen, "Gas Pressure in the End Plug Regions of the TMX-U Thermal Barrier Experiment," submitted to the J. Vac. Sci. Technol. (1983); Lawrence Livermore National Laboratory, Livermore, $C A$, UCRL-89938.

26. A. A. Marin, S. P. Auerbach, R. H. Cohen, J. M. Gilmore, L. D. Pearlstein, and M. E. Rensink, Nuc. Fus. 23703 (1983). See also D. E. Baldwin and B.G. Logan (Eds.), Physics Basis for an Axicell Design for the End Plugs of MFTF-B, Lawrence Livermore National Laboratory, Livermore, CA, UCID-19359 (1982).

27. L. D. Pearlstein, D. E. Baldwin, R. H. Cohen, T. K. Fowler, and B. G. Logan, "Stabilization of Tandem-Mirror Trapped-Particle Modes by Incomplete Cancellation of Trapped-Particle Drifts," presented at 1982 Sherwood Meeeting, Annual Controlled Fusion Theory Conference, Santa Fe, NM, April 25-28, 1982. 
2B. E. B. Hooper, Jr., D. E. Baldwin, T. K. Fowler, R, J. Kane, "and W. C. Turner, "Radial Transport Reduction in Tandem Mirrors Using End Wall Boundary Cunditions," submitced to Physics of Fluids (1984); Lawrence Livermore National Laboratory, Livermore, CA, UCRL-90639.

29. D. L. Corre11, J. A. Byers, T. A. Casper, Throttle Coil Operation of TMX-U, Lawrence Livermore National Laboratory, Livermore, CA, UCID-19650 (1983).

30. Y-J. Chen, D. E. Baldwin, and T. Q. Hua, "Analytic Model and Simulations of RE Drift Pumping of Thermal Barriers," Bull. Amer. Phys. Soc. 281195 (1983).

31. B. W. Stallard, F. H. Coensgen, W. F. Cummins, "Plasma Wall Charge Exchange Interactions in the 2 XIIB Magnetic Mirror Experiment," in Proc. International Symposium on Plasma Wall Interaction, Jitich, Federal Republic of Germany, Pergamon Press, p. 63. (1976)

32. D. L. Carrell, J. F. Clauser, F. H. Coensgen, Nuc. Fus. 20 655 (1980).

33. F. Najmabadi, and R. W. Conn, "Radius Control System for Tandem Mirrors," submitted to Nuclear Technology/Fusion (1984).

34. J. R. Farron, R. A. Breun, S. N. Golovato, "Scaling of RF Sustained Tandem Mirror Parameters With Contral Cell Heating Power Including a Central Cell Stand-Alone Mode," Bull. Amer. Phys. Soc. 27958 (1982).

35. D. Garner, private communications, May 1984.

36. S. L. Allen, C. A. Clower, and W. C. Turner, "The Influence of Vacuum and Wall Conditioning on Plasma Startup in TMX-U," Bull. Am. Phys. Soc. 281114 (1983).

37. H. F. Dylla, in Proc. of the 29th National Symposium (American Vacuum Society, Baltimore, MD).

38. S. L. Allen, C. Clower, R. P. Drake, E. B. Hooper, Jr., A. L. Hunt, R. Munger, R. J. Bastasz, W. Bauer, and W. L. Hsu, "Initial Wall Conditioning for the TMX-ll Fusion Experiment, J. Vac. Sci. Technol. A 1(2) 916 (1983).

39. J. E. Osher, G. D. Porter, L. E. Valby, Glow Discharge Cleaning Tests of MFTE-B Cryopanel Components, Lawrence Livermore National Laboratory, Livermore, CA, Quarterly Jan.-May, 1981, UCRL-50051-81-1 (1981).

40. W. L. Pickles, in Proc. of the 29 th National Vacuum Syposium (American Vacuum Society, Balrimore, MD, 1982).

41. W. Bauer, Bull. Am. Fhys. Soc. 27 II37 (1982).

42. D. T. Strand, H. W. Moos, and S. L. Allen, "Experimental Evidence for Dutward Radial Transport of Impurities from the Central Cell of TMX," Nuc. Fus. 23 (12) (1983).

43. G. E. Gryczkowski, Neutral Gas Blanket Theory as Applied to the Reference Theta Einch Reactor, Ph.0. Thesis, Univ. of Michigan, Dept. of Nuclear Engineering (1979).

44. R. P. Drake and H. W. Moss, Nuc. Fus. 19407 (1979). 
45. J. E. Osher, D. P. Grubb, and P. Poulsen, "Impurity Accumulation in a Tandem Mirror," Bull. Am. Phys. Soc. 1119 ( 3983 ).

46. L. S. Hali, Nuc. Fus. 17681 (1977).

47. B. W. Stallard, "ECRH in Tandem Mirror Machines," in Proc. of IEEE Minicourse on RF Heating and Current Drive, San Diego, $\overline{C A}$, 1983; Lawrence Livexmore National Laboratory, Livermore, GA, UCRL-89276.

4a. S. L. Allen, T. L. Yu, and T. J. Nash, "Impurity Characteristics of TMX-U," Lawrence Livermore National Laboratory, Livermore, CA, UCID-20026 (1984).

41. P. Coakley, N. Hershkowitz, and G. D. Porter, "End-Wall Plasma Characteristics in the Tandem Mirror Experiments," Nuc. Fus. 221321 (1982).

50. G. D. Porter, "Effect of Gas Recycling and Secondary Emission on the Axial Flow in an Open-Ended Device," Nuc. Fus. 22 1279 (1982).

51. K. Muraoka., M. Maeda, T. Okada, in Pros. of 6th Intl. Conf. on Plasma Surf. Int. in Cont. Fus. Devices 1984. 